\title{
Statistical Analysis of Radio Frequency Interference (RFI) Caused by Solar Radiation During Wet and Dry
}

\author{
Marhamah Mohd Shafie $^{a}$, Roslan Umar ${ }^{a *}$, Nor Hazmin Sabrib \\ a East Coast Environmental Research Institute, Universiti Sultan Zainal Abidin, Kampus \\ Gong Badak, 21300, Kuala Terengganu, Malaysia; ${ }^{b}$ Faculty of Science and Marine \\ Environment, Universiti Malaysia Terengganu, 21030 Kuala Nerus, Terengganu, \\ Malaysia
}

\begin{abstract}
Radio frequency intereference study is crucial in radio astronomy field of research in managing the background noise to avoid signal mitigation from celestial object of interest. This paper describes a correlation between solar radiation and radio signal within ultra-high frequency (UHF), which statistically deduced using Spearman correlation method. The observation was done in several location including Balai Cerap KUSZA (BCK) during dry and wet season. Solar radiation is one of meteoparameters that measured simultaneously with radio signal data using weather station. This data was analysed and compared to power level (radio signal) recorded in $\mathrm{dBm}$ during wet and dry seasons. Findings show that telecommunication services occupy the UHF band. Hence, it can be concluded that, there are still some frequencies available for radio astronomical sources including that below 400 $\mathrm{MHz}$. This allocation is suitable for solar observation, Jupiter observation, continuum observation, solar wind observation, as well as pulsar and deuterium observation and VLBI application. Statistical analysis indicate that solar radiation was significantly prominent during peaks of $382.5 \mathrm{MHz}, 1800.0$ $\mathrm{MHz}$ and $2160.0 \mathrm{MHz}$. It is largely related with a correlation of $0.6252,0.6769,0.5965$ during the wet season and only small and moderate correlation at all peaks during the dry season. This important information could be a significant contribution for radio astronomers when trying to identify the best allocation for observing radio astronomical sources in the future.
\end{abstract}

Keywords: Statistical Analysis, Radio Frequency Interference, Solar Radiation, Astronomical Sources, Wet and Dry seasons

*For correspondence: roslan@unisza.edu.my

Received: 6 Dec 2020 Accepted: 15 August 2021

(C) Copyright Shafie. This article is distributed under the terms of the Creative Commons Attribution License, which permits unrestricted use and redistribution provided that the original author and source are credited.

\section{Introduction}

Investigating Radio Frequency Interference (RFI) is a continuing concern in the field of radio astronomy. Due to rapid development in technologies and telecommunications, overcrowding of frequency users often become a challenge to radio astronomical observation (Abidin et al., 2015; Hamidi et al., 2012; Umar et al., 2015). Proper mitigation initiatives have been suggested and developed so that the astronomical radio service can still be protected (Liu et al., 2019; Pinchuk et al., 2020). The RFI monitoring system in Malaysia is yet to be developed for an extended period, as there is still no radio telescope available in the east coast of Peninsular Malaysia. Since Malaysia is located at the equator, it is consistently cloudy even during the drought season. Climate is a concern when choosing a perfect site for establishing a radio telescope in order to avoid future technical issues. A previous study on RFI in Malaysia had considered meteoparameters, such as rain, humidity, solar radiation and wind speed as some of the external RFIs for a radio telescope since it has the ability to attenuate the ambient radio signal. The effect of solar radiation on radio signal has been exemplified by (Ezekoye., 2007). The study found that the increase in attenuation depended on the seasons, Earth's surface, frequency and time. Protection of the radio astronomy service from unwanted emissions resulting from the application of wideband digital modulation should be lower, as recommended in Rec. ITU-R RA.1237-1. Details of the study regarding the levels at which interfering signals become harmful to radio astronomy observation can be found in Recommendation ITU-R RA.769. For radio astronomical observation in specific bands, 
for example deuterium (322.0-328.6 MHz), hydrogen (1400-1427 MHz) dan hydroxyl lines (1610.61613.8 MHz), the frequency must be below the astronomical line threshold power flux-density (pfd) value $-204 \mathrm{~dB}\left(\mathrm{~W} / \mathrm{m}^{2}\right),-196 \mathrm{~dB}\left(\mathrm{~W} / \mathrm{m}^{2}\right)$ and $-194 \mathrm{~dB}\left(\mathrm{~W} / \mathrm{m}^{2}\right)$ (Abidin et al., 2010; ITU, 2003).

Most RFI studies were carried out in the western part of Peninsular Malaysia, such as in Kuala Lumpur, Negeri Sembilan, Langkawi, Perak, and Selangor, which was carried out by University of Malaya since 2005 (Abidin et al., 2010; Hamidi et al., 2011; Hamidi et al., 2014; Hamidi et al., 2012; Umar et al., 2011; Umar et al., 2013; Umar et al., 2014; Umar et al., 2015; Umar et al., 2018). Several studies have studied the effect of solar radiation on radio signal attenuation (Mat et al., 2016; Sabri et al., 2017; Marhamah et al., 2018; Afifah et al., 2016). However, these studies have failed to show that solar radiation has a significant effect on radio signal. Afifah et al., 2016 found that radar signals are affected by ionised particles emitted by heat energy from the Sun. The signals received were lower during the day compared to the night. The variation was seen starting from sunrise and sunset as there were changes in signal strength. Collectively, this study outlines a critical role for the robustness of the VHF and UHF in a solar radiation environment. The higher frequency is more sensitive compared to the lower frequency due to its lower wavelength. In this case, VHF is more robust because of its low sensitivity. This study indicates that there is a relationship between solar radiation and the transmission signal, taking into account external factors that might affect the radio signal in the troposphere, which consists of meteoparameters such as wind, rainfall and atmospheric reflection. Meteoparameters that are usually associated with the attenuation of radio transmission signals are rain, wind, humidity and sometimes fog. More specifically, wet foliage causes attenuation to radio signal, whereby an increase in the system's temperature changes the signal polarization compared to dry foliage (Joshi et al., 2005).

The objective of this study is to investigate the available knowledge about the effects of the solar radiation on radio signal attenuation using a statistical method, with a focus on the UHF band. This study should serve as a reference for future studies pertaining to choosing suitable sites for establishing a radio telescope in Malaysia. This paper consists of four sections. The methodology of the study is stated in Section Methodology, while the effect of solar radiation on radio signal is proposed, and verified in Section Result. This is followed by the findings and conclusions in Section Conclusion.

\section{Methodology}

\section{Instrumentation and Procedure}

The experimental setup, shown in Fig. 1 comprises an antenna, a $1.4 \mathrm{GHz}$ low noise amplifier (LNA) and a spectrum analyser. A discone antenna optimized at $1240 \mathrm{MHz}$ was mounted on a tripod and connected via a $50 \mathrm{ohm}$ coaxial cable to the $28 \mathrm{~dB}$ gain/0.34 dB NF spectrum analyser. The antenna was designed and properly measured by (Umar et al., 2018) for this purpose. The setup was fully portable and easy to assemble. It was powered by a $12 \mathrm{~V}$ battery for the spectrum analyser. The Davis Vantage Pro2, shown in Fig. 2, was used to obtain solar radiation data at BCK. The weather station was mounted on the rooftop of the observatory and connected to the processing software running on a computer.

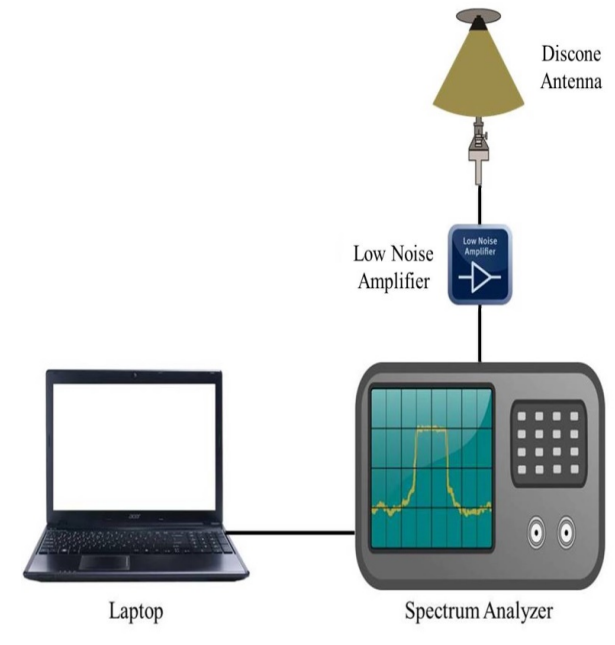

Fig. 1 Instrument Setup for RFI observation. 


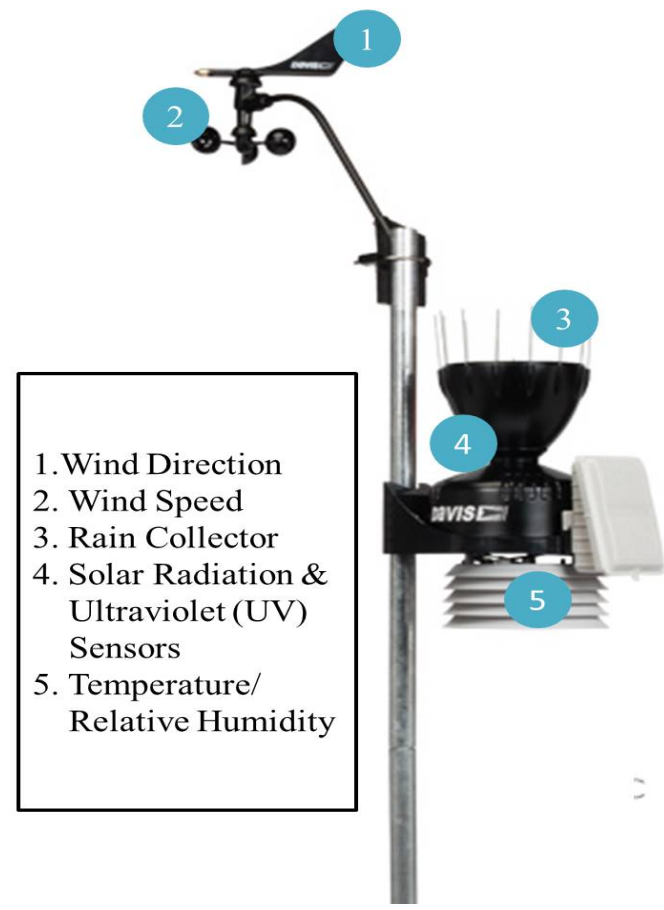

Fig. 2 Davis Vantage Pro2 device in BCK.

Based on the studies by (Mohd et al., 2017; Shafie et al., 2017), the observation period was extended to 24 hours during the wet season (January) and dry season (May) at BCK (532' 10" N $102^{\circ} 56^{\prime}$ '55" E), which is situated in the coastal area of Merang. The wet season in the east coast of Peninsular Malaysia is brought about by the North-East (NE) monsoon, while the dry season is brought about by the SouthWest (SW) monsoon. The power level in $\mathrm{dBm}$, strength for all frequencies between $300 \mathrm{MHz}$ and 3000 $\mathrm{MHz}$ were observed and recorded every one minute for an hour using the spectrum analyser (Keysight FieldFox Microwave Analyzer N9915A 9GHz) and compared for both the seasons.

\section{Site Survey}

Before data taken in BCK, preliminary studies had obtained brief RFI pattern and information to get a general idea before the main observations were conducted. Due to limited instruments and time constraint, the preliminary was done to observe radio environment below $1000 \mathrm{MHz}$, which is still within the UHF band range. As a lot of RFI monitoring have been carried out by Malaysian researchers in other places, such as Hentian Serdang (HSRDG), ESERI (ECE), Sungai Chantek (SGC) and BCK. The site selection criterion was applied for various populations; from remote areas to urban areas. It indicates the frequency allocated by telecommunication services and radio communication. It is important that the site is not off-grid and has enough facilities and infrastructure for the observer, especially power demand and internet connection.

BCK is located in a remote area $24 \mathrm{~km}$ from Gong Badak. The observatory is situated on a Merang Hill $40 \mathrm{~m}$ (160 feet) above mean sea level and nearby Merang jetty and beach of Merang less than $1 \mathrm{~km}$. This jetty provides tourist access to Redang Island, which is one of the most beautiful islands in the world. Meanwhile, ECE is located in the Universiti Sultan Zainal Abidin's (UniSZA) main campus. Another site is HSRDG, which is located in a residential area in Serdang City, Selangor where highways are present nearby. In contrast, SGC is located $10 \mathrm{~km}$ away from Jerteh City. It is located nearby a forest, old residential area and is surrounded by foliage. The average power level measured at selected sites differed from each other, as illustrated in Figure 3. In the same bandwidth, it was noticed that several radio astronomy observations below $1000 \mathrm{MHz}$ are pulsar, deuterium line (DI), solar radio burst Type I, II and III, stationary solar radio burst and moving Type IV, solar burst continua and solar burst Type V. The frequency users in HSRDG are more crowded compared to ECE, BCK and SGC. 


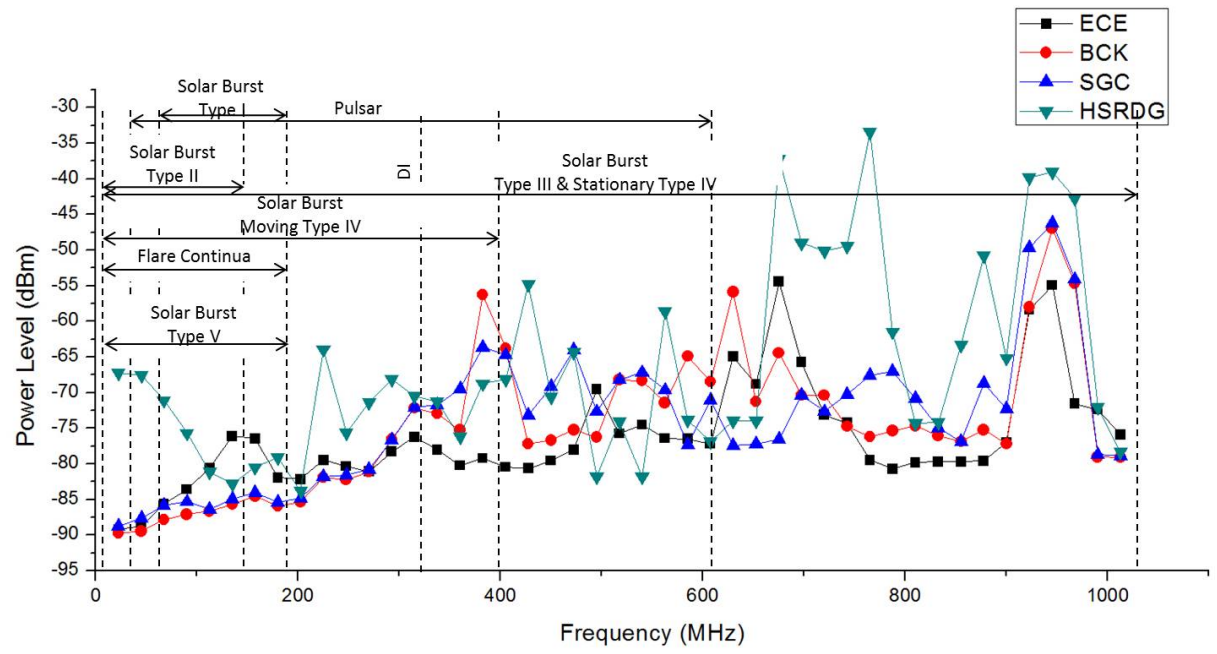

Fig. 3 Spectrum monitoring at ECE, BCK, SGC and HSRD.

According to the Malaysian Population and Housing Census (2010), the population density in Kajang, where HSRDG is located, was 342,657 people. There is a hospital located nearby the observation site, thus, increasing the population density in HSRDG due to high-traffic loads and high-end medical equipment. The population for ECE, BCK and SGC were 83,793 population $/ \mathrm{km}^{2}, 3,274$ population $/ \mathrm{km}^{2}$ and 5,655 population $/ \mathrm{km}^{2}$ respectively (DOSM, 2010). Overall, these results indicate that BCK is considered as one of the suitable places for radio astronomical observation due to its low population density and low spectrum pollution, which is 47.9707 population $/ \mathrm{km}^{2}$ compared to other sites even though power level at all these sites is low I. The high population density should increase the level of human-made RFI (Sabri et al., 2017).

\section{Results and Discussions}

\section{Radio Environment at BCK}

The spectral measurements are shown in Figure 4. In the plots, the region with no prominent peaks are labelled as region 1 (R1), region 2 (R2), region 3 (R3) and region 4 (R4). R1 is between $427.5 \mathrm{MHz}-$ 900.0 MHz, R2 is between $990.0 \mathrm{MHz}-1777.5 \mathrm{MHz}, \mathrm{R} 3$ is between $1912.5 \mathrm{MHz}-2092.5 \mathrm{MHz}$ and R4 is between $2227.5 \mathrm{MHz}-3000.0 \mathrm{MHz}$. The average power level difference between the wet season and dry season is $11.3923 \mathrm{dBm}$.

It is important to identify the prominent peaks as well as it sources in the UHF band because there are allocated bands for radio astronomical observations. Although Malaysian Communications And Multimedia Commission (MCMC) has allocated certain bands, it should be protected for the study of astronomy, while the existence of ground-based RFI still exists as it comes from human-made RFI sources. Many researchers who study radio astronomy have experienced this problem (Eatough et al., 2010; Otto et al., 2016). Another problem arises when solar radiation and some meteoparameters cause attenuation the ground base RFI, causing the average power level to be amplified.

Throughout the observation period, prominent peaks were found and identified as RFI contributors towards nearby radio astronomical objects. These prominent peaks were labelled as peak I $(382.5 \mathrm{MHz})$, II (945.0 MHz), III (1800.0 MHz) and IV (2160.0 MHz), while users of these frequencies were identified based on MCMC. Most of these prominent peaks had originated from telecommunication systems from the nearby base station as there were users from nearby residences. The source of these peaks are shown in Table 1. There are peaks detected in the R1 until R4, however the signal power level are low. There are normally comes from the telecommunication sources such as radio and television transmission, radar, radio amateur communication, military communication, air traffic control, flight communication and many more. Each of them communicates in their specific spectrum allocated by the authorities (e.g. MCMC). 


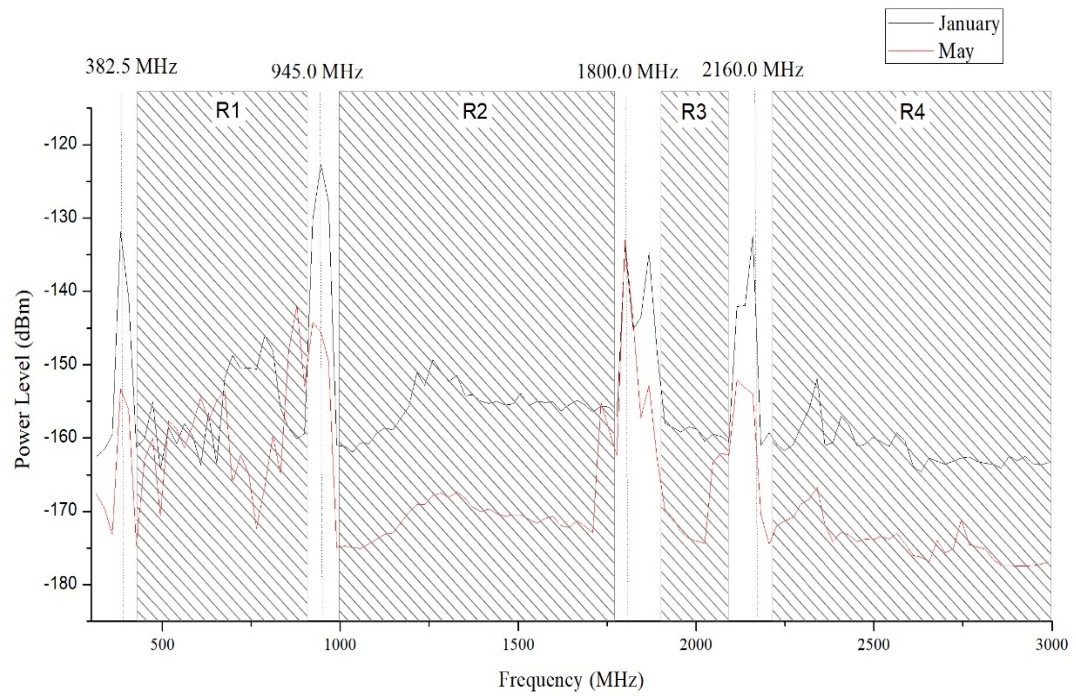

Fig. 4 Average power level at BCK and low RFI region (R).

Table 1 Peaks \& Malaysia Allocation.

\begin{tabular}{|c|c|c|}
\hline Peaks & Malaysia Allocation & Sources \\
\hline $\mathbf{I}$ & $\begin{array}{c}\text { FIXED } \\
\text { MOBILE MLA34 } \\
\text { 5.254 MLA3 MLA14 } \\
\text { MLA84 MLA93 MLA102 }\end{array}$ & Digital trunked radio \\
\hline II & $\begin{array}{c}\text { FIXED } \\
\text { MOBILE 5.317A MLA91 } \\
\text { BROADCASTING } \\
\text { 5.320 MLA3 MLA96 } \\
\text { MLA102 }\end{array}$ & Cellular mobile services [EGSM/GSM]/ [IMT] \\
\hline III & $\begin{array}{c}\text { FIXED } \\
\text { MOBILE 5.384A 5.388A MLA53 } \\
\text { MLA89 MLA91 MLA92 MLA99 } \\
\text { 5.149 5.341 5.385 5.386 } \\
\text { MLA3 MLA81 MLA90 }\end{array}$ & Cellular mobile services [EGSM/GSM]/ [IMT] \\
\hline IV & $\begin{array}{c}\text { FIXED } \\
\text { MOBILE 5.388A MLA53 MLA92 } \\
5.388\end{array}$ & Cellular mobile services IMT \\
\hline
\end{tabular}

\section{Correlation between Solar Radiation and Radio Signals}

Based on observations, the solar radiation measured was higher during January $\left(226.2535 \pm 3 \mathrm{~W} / \mathrm{m}^{2}\right)$ compared to May $\left(200.9688 \pm 3 \mathrm{~W} / \mathrm{m}^{2}\right)$. Although January was considered to be a dry season and May was a wet season, it is noted that there was rainfall on the days of the observation (January only). where the rain rate was $0.3909 \pm 2.9265 \mathrm{~mm} / \mathrm{h}$, while there was no rain in May. It was also observed that both days had a $74 \% \mathrm{RH}$. The temperature only differed slightly in January $\left(29.06 \pm 1.0235{ }^{\circ} \mathrm{C}\right)$ and May $\left(28.93 \pm 1.4273^{\circ} \mathrm{C}\right)$.

Based on Table 2, solar radiation had a significant effect on the observed peaks (Peak I, II, III and IV) and it had a large correlation with Peak I, III and IV with values of $r=0.6252, r=0.6769$ and $r=0.5965$, while Peak II had a small correlation $(r=0.1192)$ in January. Moreover, only small correlations were calculated for Peak I, II, III and IV, which yielded values of $r=-0.2860 \$, r=0.2745, r=-0.0196$ and $r=0.3393$ respectively, during May. 
Table 2 Correlation of solar radiation and radio signal.

\begin{tabular}{ccccc}
\hline Month & Peak I & Peak II & Peak III & Peak IV \\
\hline January & 0.6252 & 0.1192 & 0.6769 & 0.5965 \\
p-value & 0.0000 & 0.0017 & 0.0000 & 0.0000 \\
May & -0.2860 & 0.2745 & -0.0196 & 0.3393 \\
p-value & 0.0000 & 0.0000 & 0.6581 & 0.0000 \\
\hline
\end{tabular}

These positive and large correlations indicate that the attenuation of radio signals change as the solar radiation changes, whereby the ionised particles produced by the heat energy from the Sun effects radio signals (Taat et al., 2016). This is also consistent with the curve fit shown in Figure 5. The power level increases when solar radiation increases. This may affect RFI by making it unstable and causing interference to radio astronomical observations within the UHF range, especially $\mathrm{DI}, \mathrm{HI}$ and $\mathrm{OH}$. At higher frequencies (Peak III and IV), more signals were observed and they were largely correlated compared to lower frequencies (Peak I and II). This may be due to the existence of rainfall in January. According to Joshi et al. (2005), wet foliage causes more interference compared to dry foliage in the form of attenuation to radio signals, increasing the system's temperature and changing the signal's polarization.

\section{Conclusions}

This study determined the frequency window for UHF $(300-3000 \mathrm{MHz})$ and found that there is RFI-free allocation that exists in between (i) $427.5-900.0 \mathrm{MHz}$, (ii) $990.0-1777.5 \mathrm{MHz}$, (iii) $1912.5-2092.5 \mathrm{MHz}$ and (iv) $2227.5-3000.0 \mathrm{MHz}$. This is a very important window for radio astronomers on the ground for line and continuum observations (Hamidi et al., 2012).

The correlation between solar radiation and radio signal in an UHF band at BCK was calculated and the relationship was deduced using the statistical analysis and polynomial curve. Solar radiation is significant for prominent peaks at $382.5 \mathrm{MHz}, 1800.0 \mathrm{MHz}$ and $2160.0 \mathrm{MHz}$. It has a correlation of $0.6252,0.6769$ and 0.5965 during the wet season and only small and moderate correlation peaks in the dry season. Although well-protected, the radio observatory is still prone to satellite emissions. Therefore, unwanted releases from satellites is the most serious threat to radio astronomy services due to the rapid development of satellites today. In the future, MCMC and radio astronomers need to suggest, share and discuss the details of managing the radio astronomy spectrum.

UniSZA had started investigating RFI in Terengganu since 2015. The aim of the study was to examine the RFI pattern and to observe possible radio astronomical sources, such as solar observation, Jupiter observation, solar ionospheric disturbance (SID) and solar wind observation. UniSZA had also began collaborating with Christian Monstein, which is the Compound Astronomical Low-Cost Low-Frequency Instrument for Spectroscopy and Transportable Observatory (CALLISTO) spectrometer founder, to study solar bursts.

\section{Acknowledgement}

This study is made possible by the usage of the grants FRGS/1/2019/STG02/UNISZA/02/3(RR305). The authors gratefully acknowledge Universiti Sultan Zainal Abidin and Universiti Malaysia Terengganu for the facility, financial and experimental support of this work. Special thanks are also dedicated to other researchers Electromagnetic Research Group (EMRG) for their assistance in this work.

\section{References}

Umar, R., Abidin, Z. Z., Ibrahim, Z. A., Hassan, M. S. R., Rosli, Z., Hamidi, Z. S. 2012. Population density effect on radio frequencies interference (RFI) in radio astronomy. AIP Conference Proceedings, 1454, 1, 39-42.

Hamidi, Z.S., Shariff, N., Abidin, Z., Ibrahim, Z. and Monstein, C. 2012. Coverage of Solar Radio Spectrum in Malaysia and Spectral Overview of Radio Frequency Interference (RFI) by Using CALLISTO Spectrometer from $1 \mathrm{MHz}$ to $900 \mathrm{MHz}$. Middle-East Journal of Scientific Research, 12(6), 893-898.

Umar, R., Hazmin, S.N., Abidin, Z.Z., Ibrahim, Z.A. 2015. How to deal with radio astronomy interference. 천문학논총, 
30(2), 691-693.

Liu, Q., Wang, Y., Liu, Y., Wang, N., Liu, F., Yan, H., Wang, Y., 2019, March. Spectrum monitor system at QTT site. In 2019 URSI Asia-Pacific Radio Science Conference (AP-RASC), 1-4.

Pinchuk, P., Margot, J. 2020. Benchmarking Correlation-Based Radio Frequency Interference Mitigation in the Search for Radio Technosignatures. AAS, 227-07.

Ezekoye, B. A., Obodo, R. M. 2007. The effects of solar radiations on telecommunications. Pacific Journal of Science and Technology, 8(1), 109-117.

RA.769-2. Protection criteria used for radio astronomical measurements. (2020). Retrieved 1 November 2017, from https://www.itu.int/rec/R-REC-RA.769/en

Abidin, Z. Z., Adnan, S. B. R. S., Ibrahim, Z. A. 2010. RFI profiles of prime candidate sites for the first radio astronomical telescope in Malaysia. New Astronomy, 15(3), 307-312.

Hamidi, Z. S., Abidin, Z. Z., Ibrahim, Z. A., Shariff, N. N. M., Ibrahim, U. F. S. U., Umar, R. 2011. Preliminary analysis of investigation Radio Frequency Interference (RFI) profile analysis at Universiti Teknologi MARA. In Proceeding of the 2011 IEEE International Conference on Space Science and Communication (IconSpace), 311-313.

Hamidi, Z. S., Shariff, N. N. M. 2014. Investigation of radio frequency interference (RFI) profile and determination of potential astronomical radio sources. International Letters of Chemistry, Physics and Astronomy, 5.

Umar, R., Abidin, Z. Z., Ibrahim, Z. A. 2011. Implementing the GIS technique for RFI mapping for radio astronomy in Malaysia. In Proceeding of the 2011 IEEE International Conference on Space Science and Communication (IconSpace), 25-27.

Umar, R., Abidin, Z., Ibrahim, Z., Gasiprong, N., Asanok, K., Nammahachak, S., Aukkaravittayapun, S., Somboopon, P., Prasit, A., Prasert, N. Hamidi, Z.S. 2013. The Study of Radio Frequency Interference (RFI) in Altitude Effect on Radio Astronomy In Malaysia And Thailand. Middle East Journal of Scientific Research, 14(6), 861-866.

Umar, R., Abidin, Z. Z., Ibrahim, Z. A., Rosli, Z., Noorazlan, N. 2014. Selection of radio astronomical observation sites and its dependence on human generated RFI. Research in Astronomy and Astrophysics, 14(2), 241.

Umar, R., Sabri, N. H., Ibrahim, Z. A., Abidin, Z. Z., Muhamad, A. 2015. Measurement technique in radio frequency interference (RFI) study for radio astronomy purposes. Malaysian Journal of Analytical Sciences, 19(5), 960-965.

Umar, R. 2014. Radio frequency interference (RFI) mapping for radio astronomy in Peninsular Malaysia. Doctoral dissertation, University of Malaya.

Mat, R., Shafie, M. M., Ahmad, S., Umar, R., Seok, Y. B., Sabri, N. H. 2016. Temperature effect on the tropospheric radio signal strength for UHF band at Terengganu, Malaysia. International Journal on Advanced Science Engineering Information Technology, 2, 4

Sabri, N. H., Umar, R., Shafie, M. M., Zafar, S. N. A. S., Mat, R., Ahmad, S., Ibrahim, Z. A. 2017. Correlation analysis of tropical rainforest climate effect on radio signal strength at KUSZA observatory, Terengganu. Advanced Science Letters, 23(2), 1268-1271.

Marhamah, M. S., Umar, R., Hazmin, S. N., Zafar, S. N. A. S., Mat, R. 2018. The influence of solar radiation on radio signal at UHF band. Journal of Fundamental and Applied Sciences, 10(1S), 268-277.

Afifah, T., Ramli, F., Ahmad, S. N. A., Jusoh, M. H., Abdullah, M. 2016. Daytime and nighttime variations of VLF signal during quiet period. In 2016 IEEE Asia-Pacific Conference on Applied Electromagnetics (APACE), 55-58.

Joshi, G. G., Dietrich, C. B., Anderson, C. R., Newhall, W. G., Davis, W. A., Isaacs, J., Barnett, G. 2005. Near-ground channel measurements over line-of-sight and forested paths. IEE Proceedings-Microwaves, Antennas and Propagation, 152(6), 589-596.

Meng, Y. S., Lee, Y. H., Ng, B. C. 2009. Study of propagation loss prediction in forest environment. Progress In Electromagnetics Research, 17, 117-133.

Mohd Afandi, N.Z., Umar, R., Sabri, N.H., Abidin, Z.Z., Ibrahim, Z.A., Ishak, A.N., Nurlisman, Z.K.D., Monstein, C. 2017. Identification of solar radio burst type II and Type III for space weather monitoring. Advanced Science Letters, 23(2), 1281-1284.

Shafie, M. M., Umar, R., Sabri, N. H., Afandi, N. Z. M., Abidin, Z. 2017. Radio Environment Analysis at Balai Cerap KUSZA for Solar Burst Study. International Journal on Advanced Science, Engineering and Information Technology, 7(4), 1441-1447.

Umar, R., Hazmin, S. N., Marhamah, M. S., Aziz, A. A., Zulaikha, M. A. N., Dianah, A. R. S. N. 2018. Performance Analysis of Discone Antenna for Radio Frequency Interference (RFI) Measurement. International Journal of Engineering \& Technology, 7(3.14), 333-336.

Department of Statistic Malaysia (DOSM). 2010. Population distribution by local authority and mukims 2010. Retrieved May 16, 2018 from https://www.dosm.gov.my/v1/index.php?r=column/cone\&menu_id=bTRCSEsvSkpMbERVb3pCeE1LY3I0dz09

Eatough, R. P., Molkenthin, N., Kramer, M., Noutsos, A., Keith, M. J., Stappers, B. W., Lyne, A. G. 2010. Selection of radio pulsar candidates using artificial neural networks. Monthly Notices of the Royal Astronomical Society, 407(4), 2443-2450.

Otto, A. J., Millenaar, R. P., Van Der Merwe, P. S. 2017. Characterising rfi for ska phase 1. In Proceedings of 2016 Radio Frequency Interference: Coexisting with Radio Frequency Interference (RFI 2016). 